\title{
Desenvolvimento de um Guia Turístico Interativo
}

\author{
Lucas Freitas $^{1}$, Lis Custódio $^{2}$ \\ ${ }^{1}$ Instituto Politécnico - Universidade do Estado do Rio de Janeiro (UERJ) \\ ${ }^{2}$ Instituto de Matemática e Estatística - Universidade do Estado do Rio de Janeiro (UERJ) \\ liscustodio@ime.uerj.br
}

\begin{abstract}
Nowadays, tourists who want to visit small towns find it difficult to get to know the local sights. There is a lot of information spread across websites and social media making it difficult to quickly and objectively obtain relevant information. This difficulty becomes even greater when the desired destinations are small towns without investment in the local tourism. Using only one simple table containing the data about the tourist points of a certain region, our method is able to generate in an automated way an interactive visualization of the tourist places of that region, where you can navigate simply and intuitively to get information on local attractions and, according to user preferences, get a roadmap of attractions to see near your location. The proposed application was evaluated through a study carried out with possible users, which showed positive results regarding usability, ease of learning and satisfaction.
\end{abstract}

Resumo. Nos dias de hoje, o turista que deseja visitar pequenas cidades encontra grandes dificuldades para conhecer os pontos turísticos locais. Existem muitas informações fracionadas em diversos portais e redes sociais, dificultando a obtenção rápida e objetiva de informações relevantes. Esta dificuldade se torna ainda maior quando os destinos desejados são cidade pequenas, sem muitos investimentos no turismo local. Usando apenas uma simples tabela contendo os dados sobre os pontos turísticos de uma determinada região, nosso método é capaz de gerar de forma automatizada uma visualização interativa dos postos turísticos dessa região, onde é possível navegar de forma simples e intuitiva para obter informações sobre as atrações locais e, de acordo com as preferências do usuário, obter um roteiro de atrações para conhecer nas proximidades da sua localização. O aplicativo proposto foi avaliado através de um estudo realizado com possíveis usuários, o qual apresentou resultados positivos em relação a usabilidade, facilidade de aprendizagem e satisfação.

\section{Introdução}

Hoje em dia, apesar de termos acesso a um grande número de informações através da internet, muitas vezes estas estão espalhadas por inúmeros sites e redes sociais, fazendo com que sejam necessárias longas buscas para se obter informações sobre as atrações de um lugar que desejamos visitar. Esta dificuldade aumenta quando o objetivo é conhecer cidades fora dos grandes centros, cidades sem uma infraestrutura voltada para o turismo.

Atualmente, com grande fluxo de informações existentes, fica cada vez mais importante o uso de técnicas que permitam ampliar a percepção de um dado conjunto de informações e na área do turismo não seria diferente. Uma ferramenta computacional 


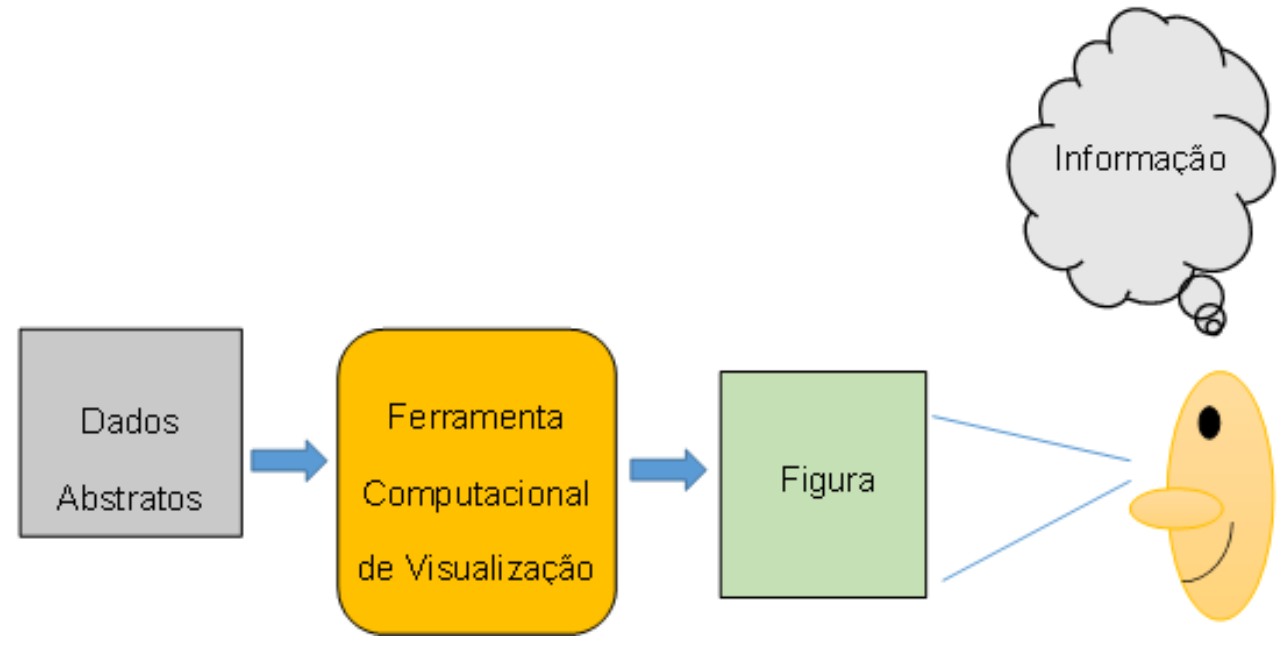

Figura 1. Processo simplificado de visualização de informações

voltada ao turismo deve apresentar, de forma simples e intuitiva, informações que permitam ao turista explorar as atrações do lugar desejado de forma a auxiliar no planejamento da viagem e na logística durante a sua estadia.

A demanda por transformar dados abstratos em imagens ou gráficos cresce a cada dia, a utilização de recursos gráficos possibilita que o ser humano capte a informação de forma mais rápida e eficiente. Essa facilidade do ser humano de processar informações através de objetos gráficos se dá porque a visão é o sentido humano que possui maior capacidade de captação de informações por unidade de tempo [Dias 2007]. Nesta direção, a Visualização da Informação pode ser definida como uma área da ciência que tem por objetivo o estudo das principais formas de representações gráficas para apresentação de informações de maneira a contribuir para uma melhor percepção e entendimento delas, além de possibilitar a dedução de novos conhecimentos com base no que está sendo apresentado [Freitas et al. 2001].

$\mathrm{Na}$ busca por construir uma visualização efetiva características como cor, dimensionalidade, perspectiva, luminosidade, tamanho e forma dos objetos são fatores que auxiliam no processo de cognição. Aspectos como existência de mecanismos de interação com os dados e a possibilidade de compactar uma grande quantidade de informações úteis em uma mesma imagem também contribuem para a efetividade de uma visualização [do Nascimento e Ferreira 2005].

Na Figura 1, apresentamos um resumo do processo de visualização de informações auxiliado por um computador. A visualização pode funcionar como uma extensão da memória humana e como um auxílio para o processo cognitivo. Por exemplo, fazemos anotações em uma agenda ou em um calendário para nos lembrarmos de assuntos a serem discutidos ou de eventos que ocorreram ou que irão ocorrer. Também desenhamos diagramas e organizamos informações espacialmente em uma folha de papel quando estamos estudando um problema que envolve diversas partes. As imagens, nos ajudam a entender o problema e/ou a encontrar uma solução para o mesmo e, inclusive, facilitam a memorização do objeto em estudo.

Um exemplo bem famoso de visualização é o mapa de M. Charles Minard, apre- 
sentado na Figura 2, que mostra a marcha de Napoleão na Rússia (1812), quando 422.000 soldados partiram da França e somente 10.000 retornaram. A marcha dos soldados é representada, por exemplo, por uma linha sobre um mapa geográfico simplificado. A largura da linha em cada ponto do mapa é proporcional à quantidade de soldados que formavam o grupo naquele percurso. A ida para Moscou e a retirada do grupo é indicada pela cor da linha. Além disso, um gráfico mostrando a queda da temperatura durante a volta de Napoleão é apresentado na parte inferior da figura, alinhado com a linha que indica a marcha dos soldados. A visualização ajuda a perceber como as condições climáticas desfavoráveis contribuíram para a mortalidade dos soldados[do Nascimento e Ferreira 2005].

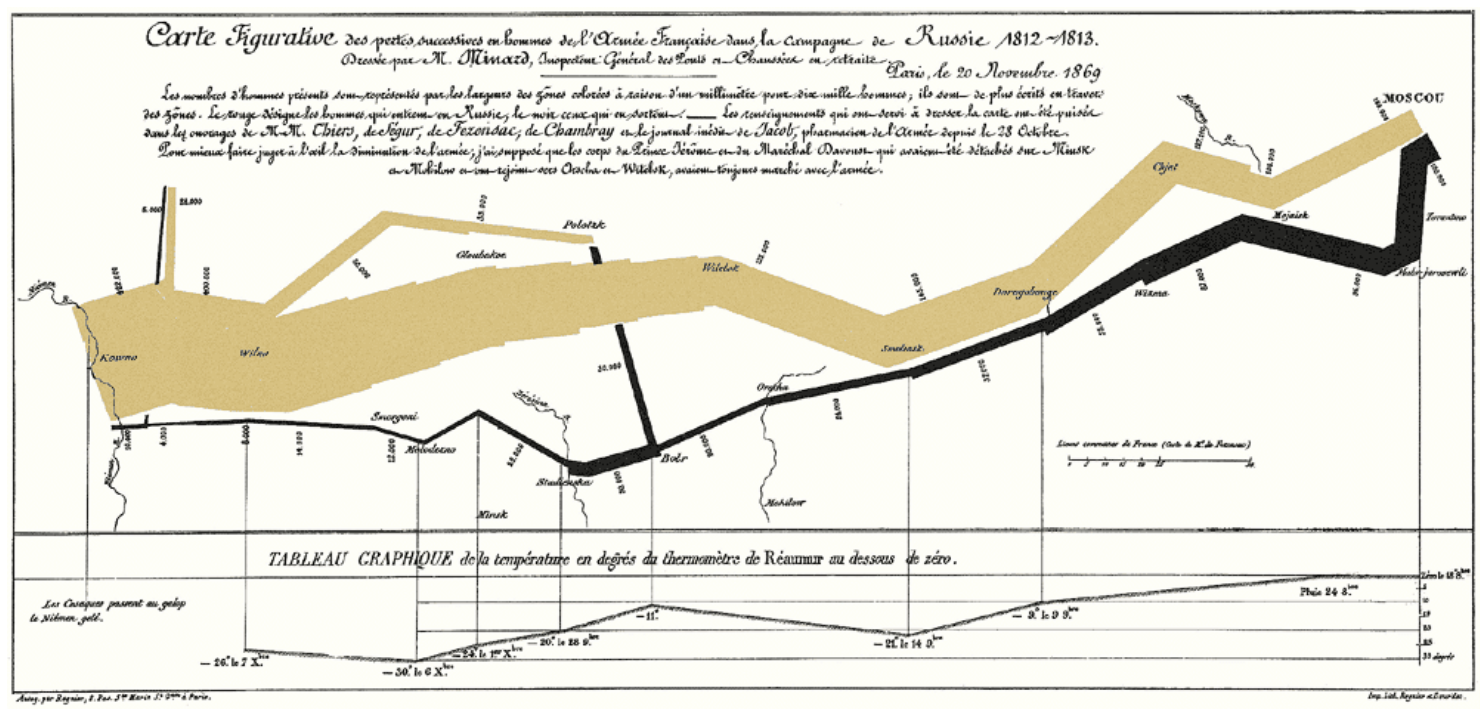

Figura 2. Mapa de M. Charles Minard

Podemos também encontrar exemplos no nosso dia a dia, como o ícone que mostra a porcentagem da bateria do smartphone, que seria muito menos eficiente se fosse apenas um campo textual, pois no decorrer da diminuição da carga o ícone vai se esvaziando mostrando de forma clara e intuitiva que a bateria está diminuindo sua carga.

No campo geográfico a visualização de informações está sempre presente, como na visualização de mapas. Hoje quando pesquisamos um ponto no Google Maps, por exemplo, temos um marcador no mapa que nos mostra o ponto que pesquisamos. Mas por trás disso temos muitos dados sendo usados para chegar ao ponto de mostrar o marcador com o local desejado de forma intuitiva no mapa. Por exemplo, esse ponto possui coordenadas geográficas (latitude e longitude) que são objetos numéricos. Imagina como seria ineficiente se ao pesquisarmos um ponto obtivéssemos apenas as coordenadas geográficas dele.

Este trabalho está estruturado da seguinte forma: no Seção 2 abordaremos a visualização de informações aplicada ao turismo, na Seção 3 apresentaremos os fundamentos do método proposto para o desenvolvimento do guia turístico interativo, na Seção 4 apresentamos os nossos resultados e as funcionalidades do guia turístico gerado e por fim, na Seção 5, apresentamos nossa conclusões e propostas de trabalhos futuros. 


\section{Visualização de informações aplicada ao turismo}

$\mathrm{Na}$ área do turismo, hoje temos o site TripAdvisor ${ }^{1}$, que possibilita ao usuário pesquisar informações como hotéis, restaurantes e pontos turísticos numa determinada região. Nessa ferramenta é possível o usuário visualizar no mapa os pontos pesquisados. Numa pesquisa no município de Nova Friburgo - RJ, foi obtido resultado mostrado na Figura 3 onde é possível observar que a ferramenta mostra ícones azuis para representar hotéis e roxos para representar restaurantes. Como se pode perceber, é uma forma intuitiva de mostrar os resultados, pois se o resultado fosse uma simples lista textual, não seria nada intuitivo para o usuário final ter uma ideia da localização dos pontos desejados.

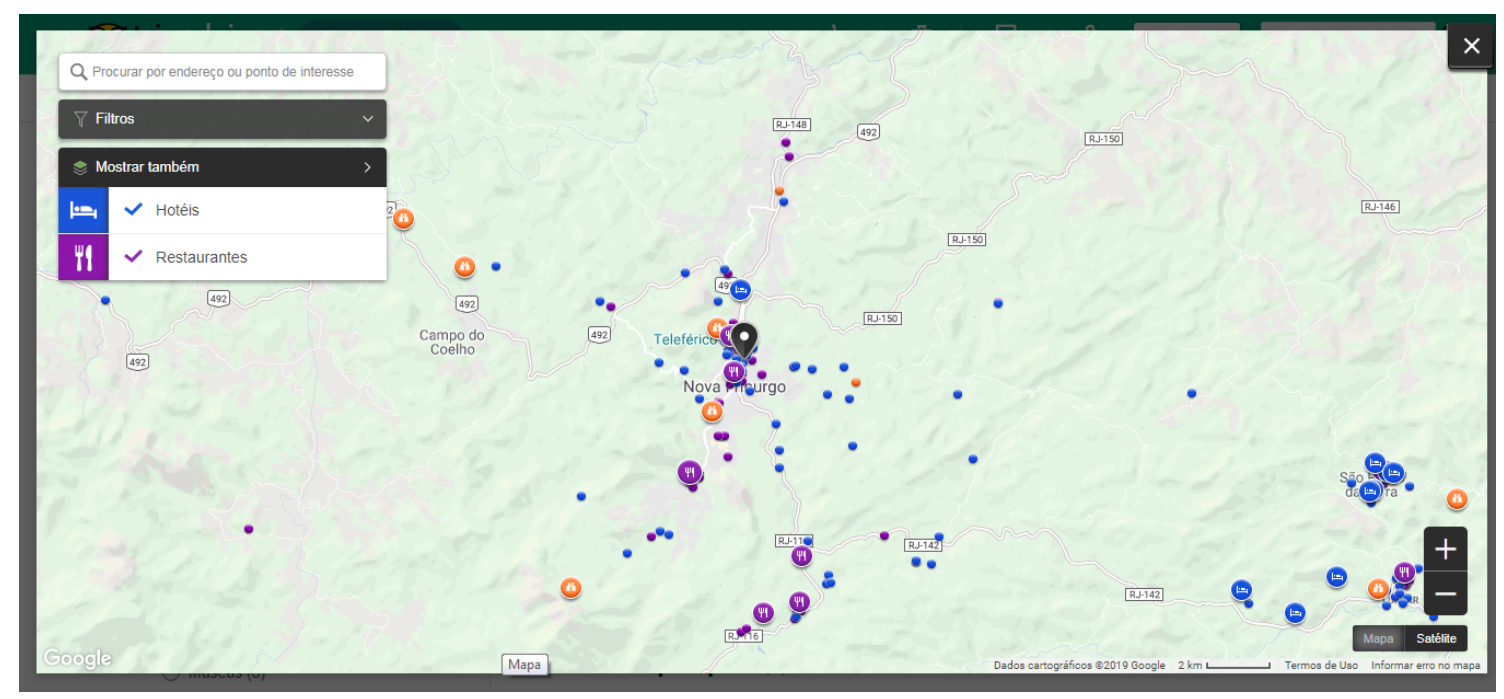

Figura 3. Ícones diferentes por categorias

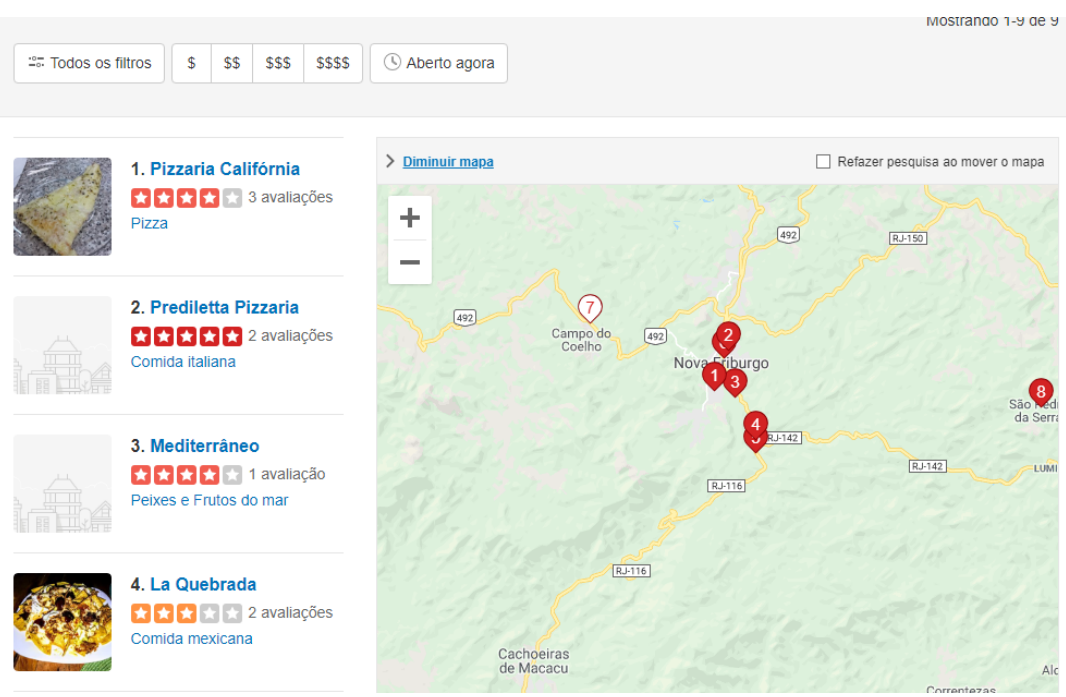

Figura 4. Ferramenta Yelp:Exemplo de pesquisa feita no município de Nova Friburgo

O Yelp ${ }^{2}$ é outra ferramenta que utiliza visualização de informações, o foco dessa ferramenta é mostrar pontos comerciais de determinada cidade que o usuário pesquisar.

\footnotetext{
${ }^{1}$ https://www.tripadvisor.com.br

${ }^{2}$ https://www.yelp.com.br
} 
Fazendo uma pesquisa na ferramenta, obtêm-se pontos da cidade como restaurantes e bares numa lista e, paralelo a lista, tem-se um mapa com os pontos marcados. Diferentemente do TripAdvisor aqui os pontos não são diferenciados no mapa por categorias, são apenas plotados no mapa com o número correspondente ao resultado obtido.
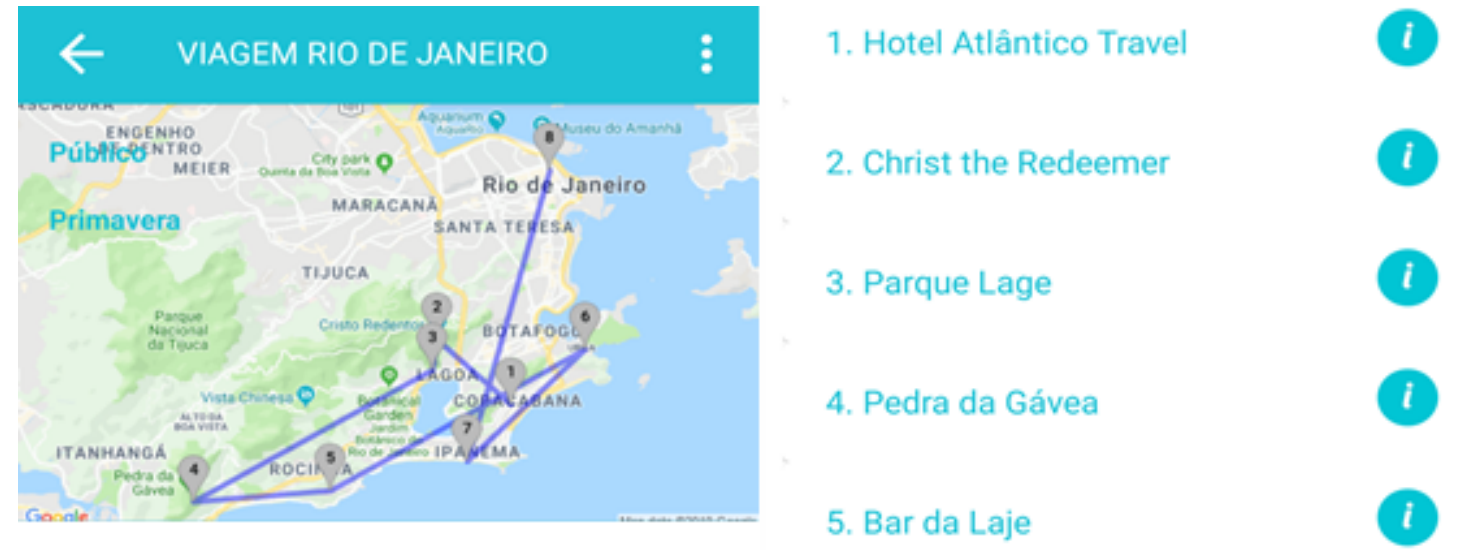

Figura 5. Ferramenta Birdymee: Roteiro pesquisado na cidade do Rio de Janeiro

Uma ferramenta focada em roteiros turísticos é o Birdymee ${ }^{3}$, é um aplicativo onde o usuário pode criar um roteiro de forma manual ou pesquisar roteiros criados por outros usuários. Como o foco é a criação do roteiro, os roteiros existentes são mais focados nas grandes cidades, com isso, usuários que desejam conhecer cidades menores deverão criar seus roteiro fazendo uma boa pesquisa em sites e nas redes sociais sobre os pontos turísticos da cidade escolhida, assim a ferramenta se torna mais viável para quem já conhece os pontos anteriormente e só usará a ferramenta para organiza-los na forma de um roteiro.

No TripAdvisor existe muita informação mas não há a opção de gerar um roteiro. Entretanto, o Birdymee tem a opção de roteiro, porém são pontos turísticos escolhidos aleatoriamente pelo usuário. Já no Yelp o foco é maior nos pontos comerciais, porém não existe a função de criar um roteiro, mostrando a apenas os pontos no mapa.

Como veremos na Seção 4 o método proposto neste trabalho é capaz de gerar uma visualização interativa que possibilita que o usuário navegue pelos pontos turísticos no mapa de forma clara, pois estarão diferenciados de acordo com sua categoria, além da possibilidade de gerar um roteiro com base nas suas categorias de interesse e em sua localização atual.

\section{Conceitos Preliminares}

Neste trabalho propomos a criação a uma visualização interativa dos pontos turísticos de uma determinada região e das informações a eles relacionadas, permitindo que usuário navegue de forma intuitiva pela visualização gerada. A visualização é gerada na forma de um aplicativo web que pode ser acessado tanto do celular quanto de um computador.

Além da agilidade na visualização dos pontos, o guia turístico gerado conta com uma função pouco vista em outros serviços de turismo em geral, a função de sugerir um

\footnotetext{
${ }^{3}$ http://www.birdymee.com.br
} 
roteiro com base nas escolhas do usuário como as categorias que deseja visitar (Arte, Parque, Rio etc) e o raio (em quilômetros) da região que ele deseja visitar.

Com o auxílio da teoria dos grafos, a ferramenta sempre apresentará um roteiro personalizado, dependendo de onde o usuário estiver e as categorias de pontos turísticos que deseja visitar, não ficando presa a roteiros pré-definidos como os encontrados em sites e ferramentas computacionais voltados para o turismo.

Dado um conjunto de pontos turísticos, o problema de se encontrar um roteiro passando por todos os pontos desse conjunto e voltando para o ponto de partida, consiste em encontrar um ciclo hamiltoniano em um grafo cujos seus vértices representam os pontos turísticos e suas arestas, o caminho entre eles. Um caminho hamiltoniano num grafo é um caminho onde ocorrem todos os vértices do grafo exatamente uma vez. Analogamente, um ciclo hamiltoniano é um ciclo que contém todos os vértices do grafo exatamente uma vez, com exceção dos vértices inicial e final que têm de coincidir. Um grafo diz-se hamiltoniano se possuir algum ciclo hamiltoniano. A seguir apresentamos os conceitos utilizados no desenvolvimento do método proposto.

\subsection{Algoritmos do vizinho mais próximo}

Neste trabalho, por sua simplicidade de implementação e baixo custo computacional, foi utilizado o algoritmo do Vizinho Mais Próximo para encontrar um caminho mínimo que passe por um conjunto de pontos turísticos selecionados pelo usuário. A partir de um ponto inicial, a localização do usuário, o algoritmo retorna a ordem dos pontos a serem percorridos pelo usuário.

O algoritmo do vizinho mais próximo foi, na ciência da computação, um dos primeiros algoritmos utilizados para encontrar caminhos hamiltonianos em grafos. Ele gera rapidamente um caminho curto, mas geralmente não o caminho ótimo. No entanto, em nossos experimentos pudemos verificar o seu bom desempenho em determinar um roteiro a ser seguido pelo usuário.Apresentamos na Figura 6, o algoritmo do vizinho mais próximo.

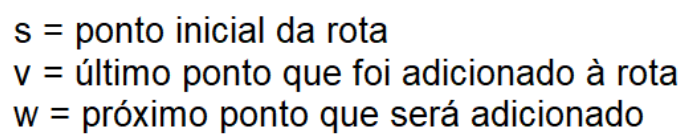

PASSO 1: Marcar todos os nós como não visitados

PASSO 2: Escolher algum nó s como ponto de partida, e marcar s como visitado. Fazer $v=s$.

PASSO 3: Repetir enquanto houver nós a serem visitados: Escolher o nó w não visitado mais próximo de $v$. Marque $\mathrm{w}$ como visitado. Estabelecer ligação entre $v \mathrm{e} w \mathrm{e}$ fazer $\mathrm{v}=$ W.

PASSO 4: Estabelecer a ligação do nó v até o nó s, para concluir o clico

Figura 6. Algoritmo do vizinho mais próximo.

Neste algoritmo, parte-se de um vértice de origem e os vértices são um a um gradativamente incorporados ao resultado. Sua ideia principal consiste em ordenar os vértices adjacentes ao vértice incorporado mais recentemente no resultado em ordem decrescente de custos e incluir no resultado o vértice com menor custo. Sendo assim, para cada vértice 
visitado, uma nova lista dos vértices mais próximos é construída até que todos os vértices sejam visitados. A complexidade desse algortimo é $O\left(n^{2}\right)$ sendo $n$ o número de vértices [da Silva Júnior 2013].

\subsection{Dados de entrada}

Apresentamos na Tabela 1 a descrição dos campos que compõem a tabela de entrada do nosso método.

\begin{tabular}{|l|l|}
\hline Nome & Nome do Local \\
\hline Categoria & $\begin{array}{l}\text { Pode ser classificado nas seguintes categorias: } \\
\text { Arte, Rio, Parque, Praça, Trilha, Praia, Museu, } \\
\text { Acampamento, Lagoa, Monumento, Galeria }\end{array}$ \\
\hline Bairro & Bairro onde está localizado o ponto turístico \\
\hline Endereço & Logradouro do ponto turístico \\
\hline Horário & Horário de funcionamento \\
\hline Telefone & Telefone do ponto turístico \\
\hline Telefone2 & $\begin{array}{l}\text { Telefone do ponto turístico } \\
\text { (caso ele possua mais de um telefone) }\end{array}$ \\
\hline Site & Site do ponto turístico \\
\hline Observação & Observação sobre o ponto turístico \\
\hline Imagem & Link para alguma imagem do ponto turístico \\
\hline Fonte & Fonte das iformações do ponto turístico \\
\hline Id Instagram & $\begin{array}{l}\text { Id do instragram do ponto turístico, } \\
\text { para o usuário poder ver fotos de usuários } \\
\text { do instagram fotografadas no ponto turístico }\end{array}$ \\
\hline Latitude & Latitude do ponto turístico \\
\hline Longitude & Longitude do ponto turísico \\
\hline
\end{tabular}

Tabela 1. Descrição dos campos da tabela onde são cadastrados os pontos turísticos

O método proposto neste trabalho tem como entrada uma tabela contendo uma lista de pontos turístico de uma dada região e algumas informações eles relacionadas. Com foco em cidade de menor infraestrutura, a nossa proposta é que a tabela de entrada seja preenchida por pessoas ou instituições que desejam impulsionar o turismo local.

\subsection{Etapas na construção da visualização interativa}

A seguir, apresentamos as etapas do nosso método no desenvolvimento de um guia turístico interativo.

- Verificação as informações contidas na tabela de entrada. Nesta etapa é verificado se a tabela de entrada foi corretamente preenchida. Detectando, por exemplo, se todas as informações necessárias de um ponto turístico foram preenchidas e se a coluna Categoria possui como entradas apenas nomes entre as categorias listadas na Tabela 2. Um ponto turístico cujas as informações não foram preenchidas corretamente não aparecerá na visualização gerada. 
- Geração de informações adicionais. Nesta fase, as informações contidas na tabela de entrada são utilizadas para gerar informações adicionais necessária, para gerar a visualização. Por exemplo, são obtidas as coordenadas geográficas do ponto turístico a partir do endereço informado na tabela.

- Classificação dos pontos turísticos em relação às suas categorias. Para a permitir que todo o processo da geração da visualização ocorra de forma automatizada, definimos um conjunto de categorias (apresentadas na Tabela 2) nas quais devem se enquadrar os pontos turísticos cadastrados. Ao ler a tabela de entrada, a ferramenta identifica quais são as categorias relacionadas ao pontos turísticos da região e passa a utilizá-las na seleção dos ícones que irão representar os pontos turísticos (Figura 7). Essa informação também será utilizada para a criação de um roteiro baseado nas escolhas do usuário, como veremos a seguir.

- Criação da visualização interativa. Uma vez obtidas as informações necessárias para a visualização e classificados os pontos turísticos, é gerada a visualização inicial centrada no baricentro das coordenadas geográficas dos pontos turísticos informados na tabela de entrada.

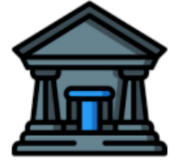

ARTE

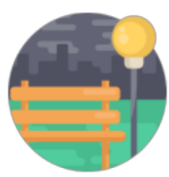

PRAÇA

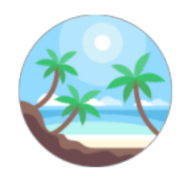

PRAIA

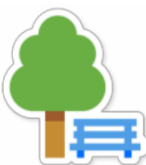

PARQUE

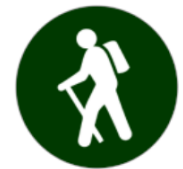

TRILHA

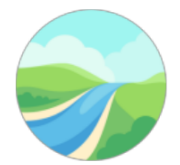

RIO

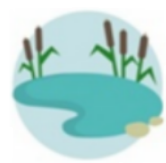

LAGOA

Figura 7. Ícones utilizados na visualização dos pontos turísticos.

Vale ressaltar que todos os dados visualizados na ferramenta são os dados presentes da tabela, ou seja, caso trocássemos a tabela com os dados de Nova Friburgo por dados de outra cidade, desde que a nova tabela possua todos com campos necessários, a ferramenta seria capaz de gerar a visualização dos pontos na nova cidade.

\section{Resultados}

Para ilustrar as funcionalidades da ferramenta proposta, utilizou-se como entrada uma tabela com os pontos turísticos da cidade de Nova Friburgo, do estado do Rio de Janeiro.

Ao abrir a ferramenta, na tela inicial, é possível ver os pontos turísticos cadastrados com seus ícones diferenciando suas categorias como demostrado na (Figura 8). Nota-se que por padrão a opção "Minha Localização" vem marcada, com ela marcada um ícone azul aparece no mapa indicando a localização do usuário. Também por padrão, todas as categorias são exibidas no mapa, mas o usuário pode a qualquer momento filtrar quais categorias deseja visualizar.

Na tela inicial ao ver os pontos no mapa, o usuário pode a qualquer momento clicar em qualquer um dos pontos para obter informações sobre o mesmo. Ao clicar num determinado ponto aparecerá sobre o ponto um popup com as informações relacionadas a ele, como o nome do ponto turístico, a imagem cadastrada, uma breve descrição sobre o ponto, o telefone de contato (Figura 8). O popup mostrará todas as informações relacionadas ao ponto cadastradas na tabela de entrada. 
Dentro do popup é possível acessar outras fotos do local através de um link para a página no Instagram ${ }^{4}$ associada ao local. Com isso, o usuário da ferramenta poderá ver fotografias capturadas por outros visitantes do local.
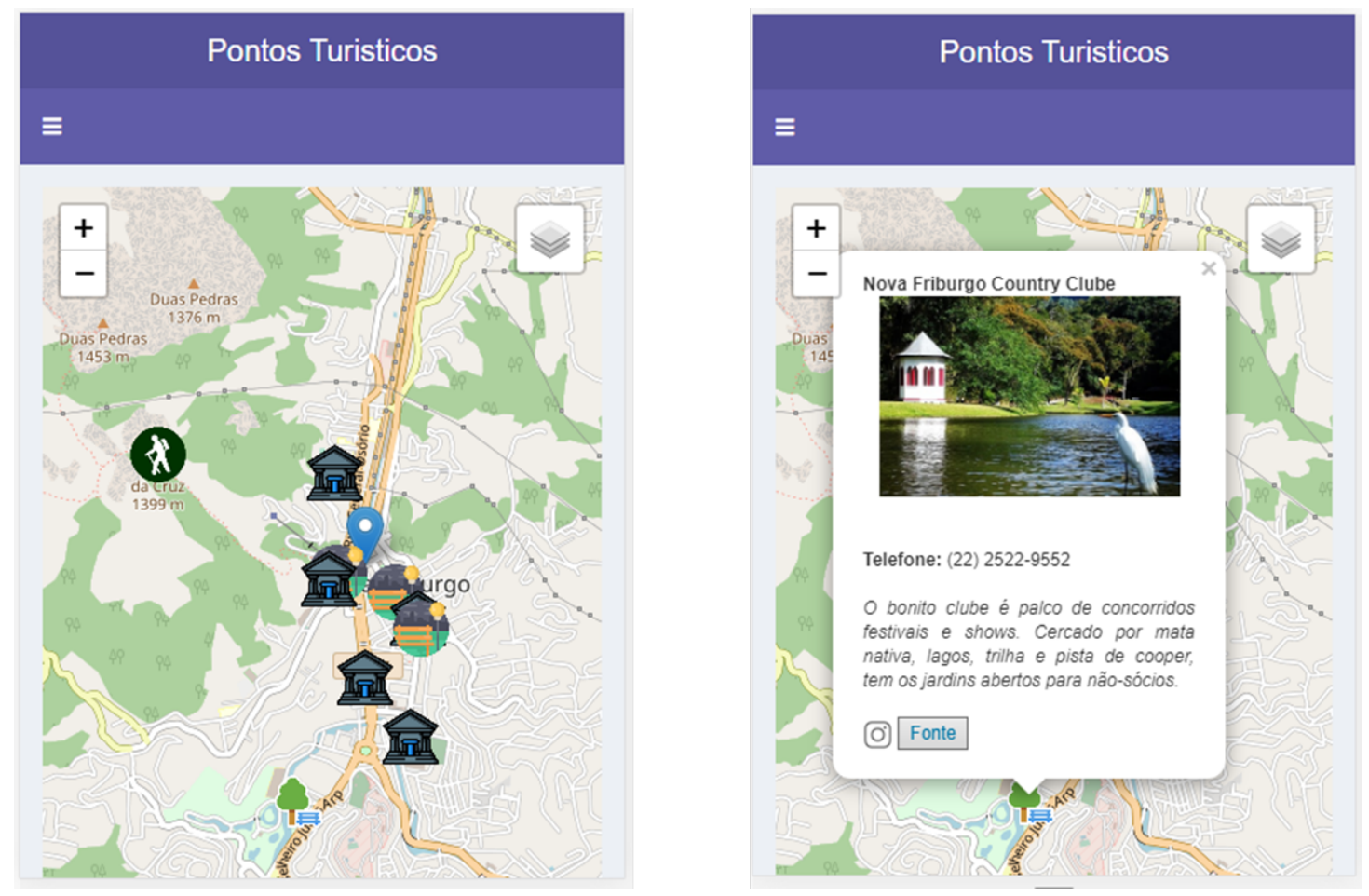

Figura 8. Tela Inicial na versão mobilie, cidade de Nova Friburgo - RJ.

\subsection{Criação de roteiros baseados na localização e escolhas do usuário}

Na Figura 9 apresentamos as etapas da geração de um roteino na ferramenta. Ao clicar na opção Roteiro do menu principal, se abrirá uma tela onde o usuário irá selecionar as categorias de pontos turísticos que tem interesse em visitar e a distância a partir da sua localização que deseja percorrer. Com os filtros, o usuário pode escolher quais categorias tem interesse em visitar, sendo as categorias presentes são as mesmas atribuídas aos pontos na tabela de entrada, e escolher o raio em quilômetros da região que deseja conhecer. A ferramenta traçará um roteiro mostrando apenas pontos das categorias que ele escolher, dentro do raio determinado a partir da sua localização.

Após preencher os requisitos para geração do roteiro o usuário deve clicar no botão roteiro presente na janela aberta. É possível ver no mapa (Figura 10) que os ícones são diferentes da tela inicial, onde mostravam ícones para cada tipo de categoria, agora os ícones são números que representam a ordem de visitação do roteiro.

O roteiro é gerado através do algoritmo do vizinho mais próximo, apresentado da Seção 3. Os pontos turísticos e a localização do usuário são vistos como vértices de um grafo ponderado e as rotas entre os pontos turísticos são as arestas desse grafo, sendo as distâncias entre os pontos os pesos atribuídos às arestas. O algoritmo encontra um caminho eficiente para o usuário visitar os pontos turísticos dentro dos parâmetros selecionados na criação do roteiro, tendo como origem a localização do usuário.

\footnotetext{
${ }^{4}$ https://www.instagram.com
} 

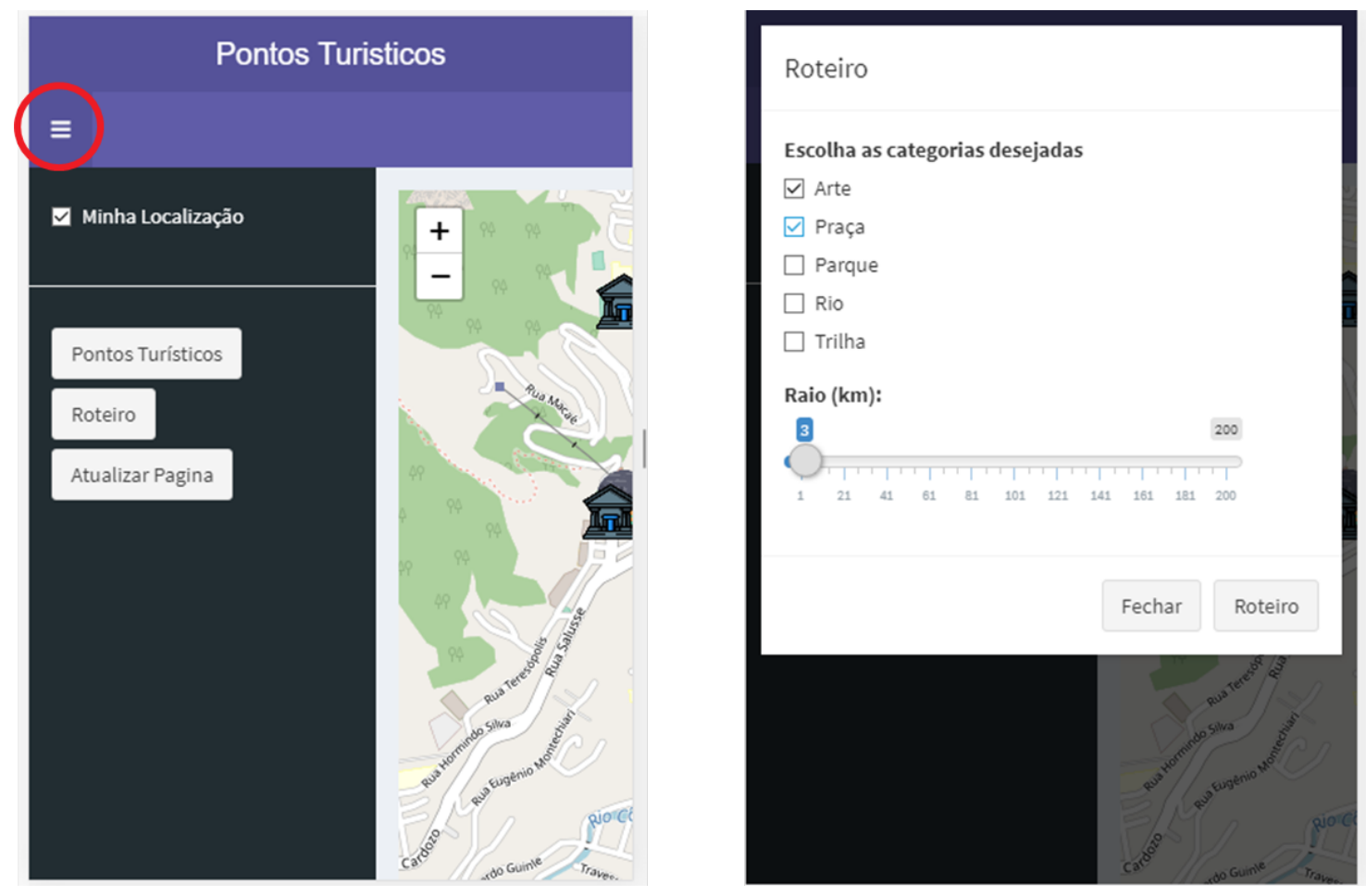

Figura 9. Criação de roteiros
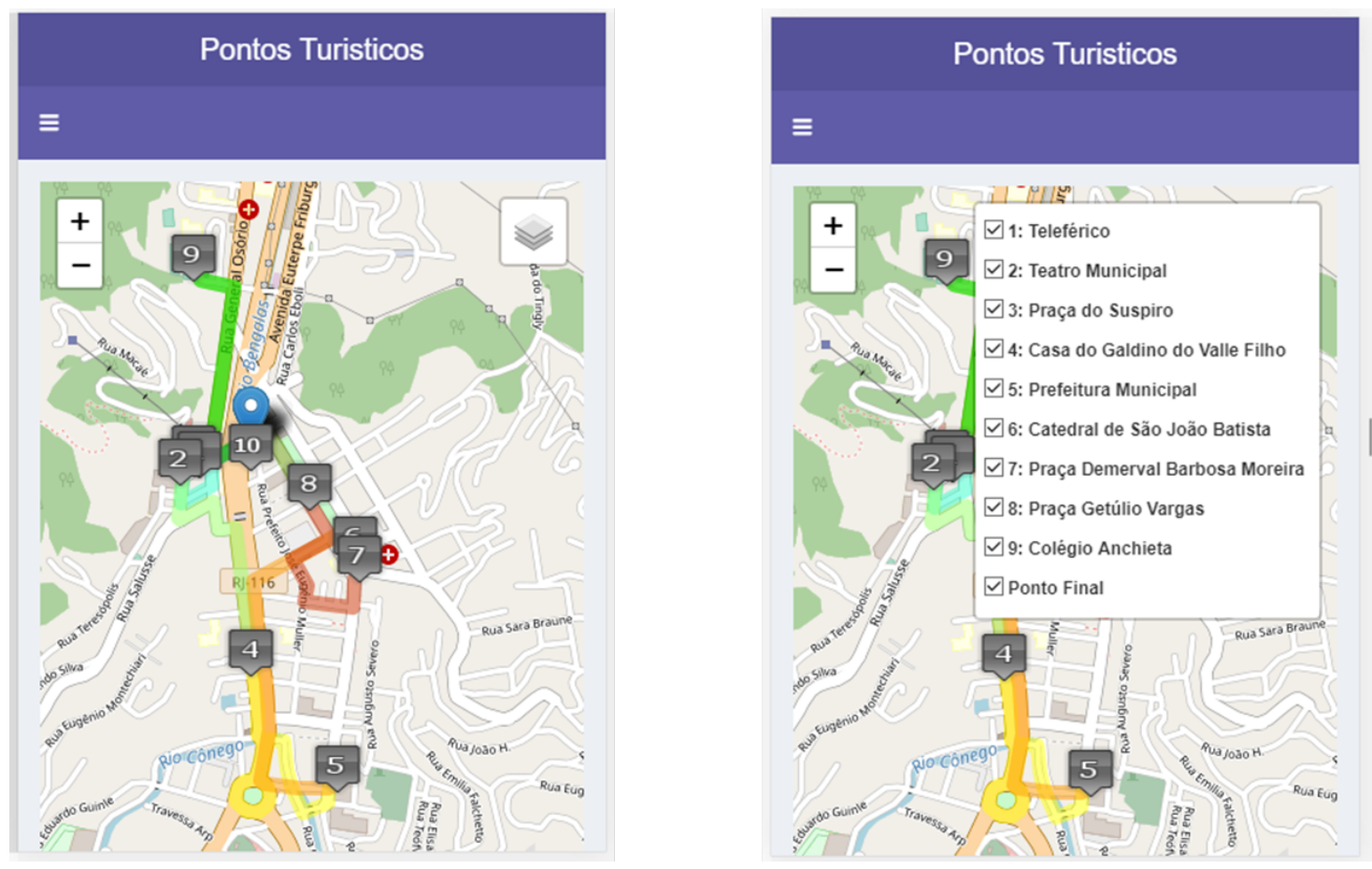

Figura 10. Visualização de um roteiro gerado pela ferramenta.

Para obtenção das rotas e distâncias entre os pontos turísticos foram feitas consultas ao Open Street Map [OSM ], uma das maiores bases de dados geográficos abertos do mundo. Nessa base é possível obter uma vasta quantidade de dados referentes a um determinado local, desde as coordenadas geográficas (latitude e longitude) como até mesmo 
as rotas entre locais. Um exemplo que mostra que os dados são confiáveis é a utilização do Open Street Map em órgãos importantes como o INPE - Instituto Nacional de Pesquisas Espaciais (BR), INDE - Infraestrutura Nacional de Dados Espaciais (BR) e o NPS National Park Service (USA).

O Open Street Map disponibiliza para desenvolvedores uma API para facilitar a obtenção dos dados geográficos. Para esta ferramenta, a API foi de suma importância, pois foi implementada na elaboração da função do roteiro sugerido, na qual, ao fazer uma chamada na API com as coordenadas do ponto de origem e as coordenadas do ponto final, a API pode retornar a rota entre os pontos como também a distância entre os pontos (em quilômetros) e o tempo sugerido do trajeto sendo percorrido de carro. Como os pontos turísticos já são conhecidos, pois estão presentes na tabela de entrada da ferramenta, um pré-processamento é feito para obter todas as rotas e distâncias entre os pontos. Com isso, quando o usuário for solicitar seu roteiro, a ferramenta filtrará das distâncias já obtidas somente as distâncias entre os pontos turísticos desejados e fará apenas uma consulta ao Open Street Map, para acrescentar a distância e a rota do turista até os locais. Após ter as distâncias necessárias, a ferramenta utiliza o algoritmo do vizinho mais próximo para obter a ordem da visitação dos locais.

\subsection{Avaliação do Aplicativo}

Para avaliar o Guia Turístico, foi realizado um estudo com possíveis usuários do aplicativo. Nesse estudo, foi utilizado um teste que avalia pontos como usabilidade, facilidade de aprendizado e satisfação dos usuários. O processo de avaliação consiste em um formulário com perguntas sobre o usuário, como nome, gênero e idade. E perguntas relacionadas à experiência do usuário no aplicativo.

Para responder as questões sobre a usabilidade da ferramenta os usuários receberam quatro tarefas (apresentadas na Tabela 2), para serem realizadas antes de responderem o questionário, além de um vídeo demonstrativo do Guia Turístico. Ao todo são oito questões múltipla escolha e duas perguntas discursivas. As questões de múltipla escolha são definidas em uma escala Likert de cinco pontos, variando de "nem um pouco" (0) a "muito" (5). Já nas perguntas discursivas o usuário pode relatar problemas na utilização da ferramenta de forma detalhada e informar quais melhorias ou sugestões gostaria de propor para o aplicativo.

$\mathrm{O}$ experimento foi feito com um grupo de 10 pessoas com idades variando entre 24 e 41 anos (média de 30 anos), onde 60\% são do gênero feminino e $40 \%$ masculino. Os usuários ficaram à vontade para fazerem as tarefas e responderem o formulário no tempo necessário para cada um. Vale ressaltar que $80 \%$ dos usuários utilizaram um smartphone e $20 \%$ um dispositivo computador para realizar os testes.

Para a visualização dos resultados, foi escolhido boxplot, que é um gráfico exploratório utilizado para mostrar a distribuição de um conjunto de dados. Através dele, podemos extrair as seguintes métricas de um conjunto: o mínimo, o primeiro quartil, a mediana, o terceiro quartil e o máximo [DALGAARD 2018].

Os resultados das quatro questões, relacionadas à usabilidade do aplicativo, podem ser vistos na Figura 11, onde as questões foram respectivamente "Você achou o aplicativo fácil de usar?", "Você se sentiu estimulado a continuar utilizando o aplicativo?", "Você agiu de forma espontânea sem ter que pensar muito?" e "A experiência foi agradável?". 


\begin{tabular}{|l|l|}
\hline Tarefa 1 & $\begin{array}{l}\text { Abrir o aplicativo e clicar em alguns pontos turísticos para ver as } \\
\text { informações detalhadas de cada um. }\end{array}$ \\
\hline Tarefa 2 & $\begin{array}{l}\text { Filtrar os pontos turísticos no mapa de acordo com sua categoria. } \\
\text { Os filtros ficam localizados no canto superior direito. }\end{array}$ \\
\hline Tarefa 3 & $\begin{array}{l}\text { Selecionar o a opção "Roteiro" no menu, escolher quais categorias deseja } \\
\text { visitar e determinar o raio da região deseja percorrer a partir da sua } \\
\text { localização (por exemplo 1 ou 2km). Escolhidas as informações, clicar no } \\
\text { botão "Roteiro" e aguardar a construção do roteiro otimizado. Caso esteja } \\
\text { utilizando um smartphone clique no botão no canto superior } \\
\text { esquerdo para abrir o menu. }\end{array}$ \\
\hline Tarefa 4 4 & $\begin{array}{l}\text { Filtrar quais rotas deseja visualizar no mapa. Utilize o botão no canto } \\
\text { superior direito. Na tela do roteiro cada ponto esta sendo representado } \\
\text { de acordo com sua ordem no trajeto, onde cada rota é representada com uma } \\
\text { cor diferente. }\end{array}$ \\
\hline
\end{tabular}

Tabela 2. Tarefas sugeridas ao usuários

Percebe-se que nas quatro questões as respostas foram positivas, onde mais de $75 \%$ avaliaram com uma nota 4 ou superior.

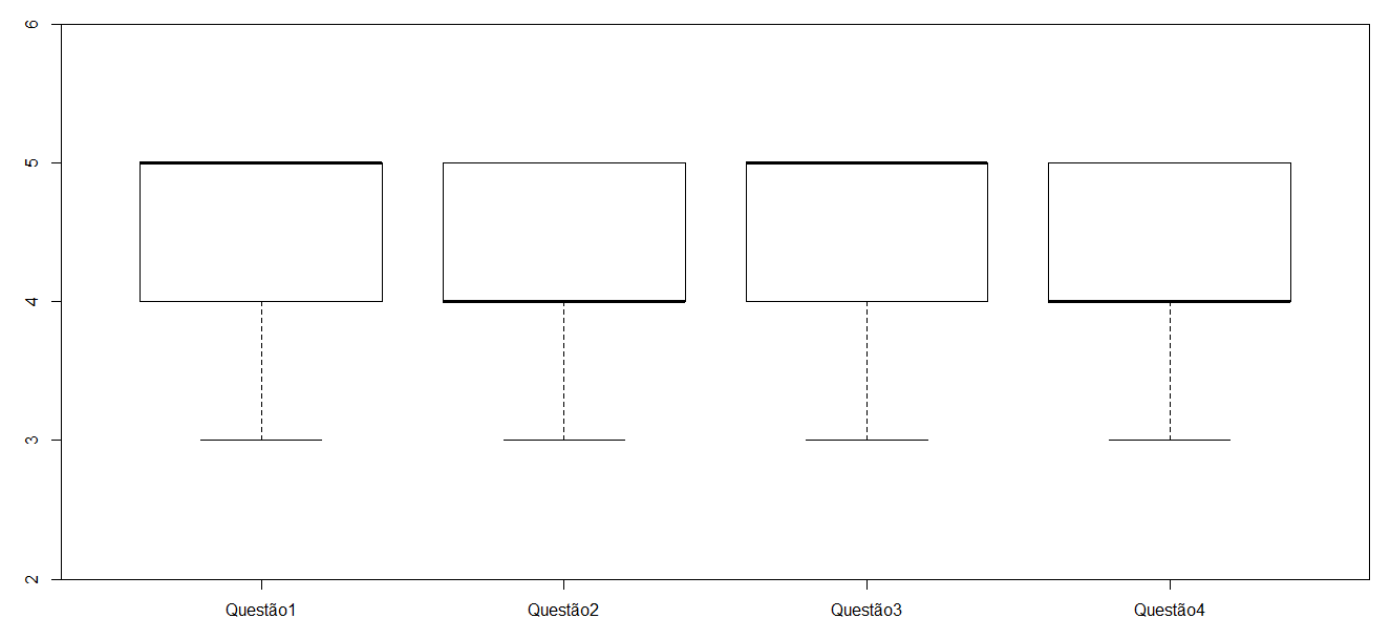

Figura 11. Resultado da avaliação com usuários referente à usabilidade do aplicativo.

Os resultados das duas questões relaciodanas à facilidade de aprendizado podem ser vistos na Figura 12. As questões são, respetivamente, "Você acha que a maioria das pessoas aprenderia a utilizar o sistema rapidamente?", "O quanto você gostaria de utilizar o sistema se um grande número de pessoas passasse a utiliza-lo frequentemente?". Podese notar que as repostas também foram positivas onde mais de $75 \%$ dos usuários avaliaram uma resposta 4 ou superior.

Nas duas questões relacionadas à satisfação dos usuários, é perguntado se o usuário recomendaria o aplicativo para um amigo e se ele se sentiu desenteressado ao utilizar 


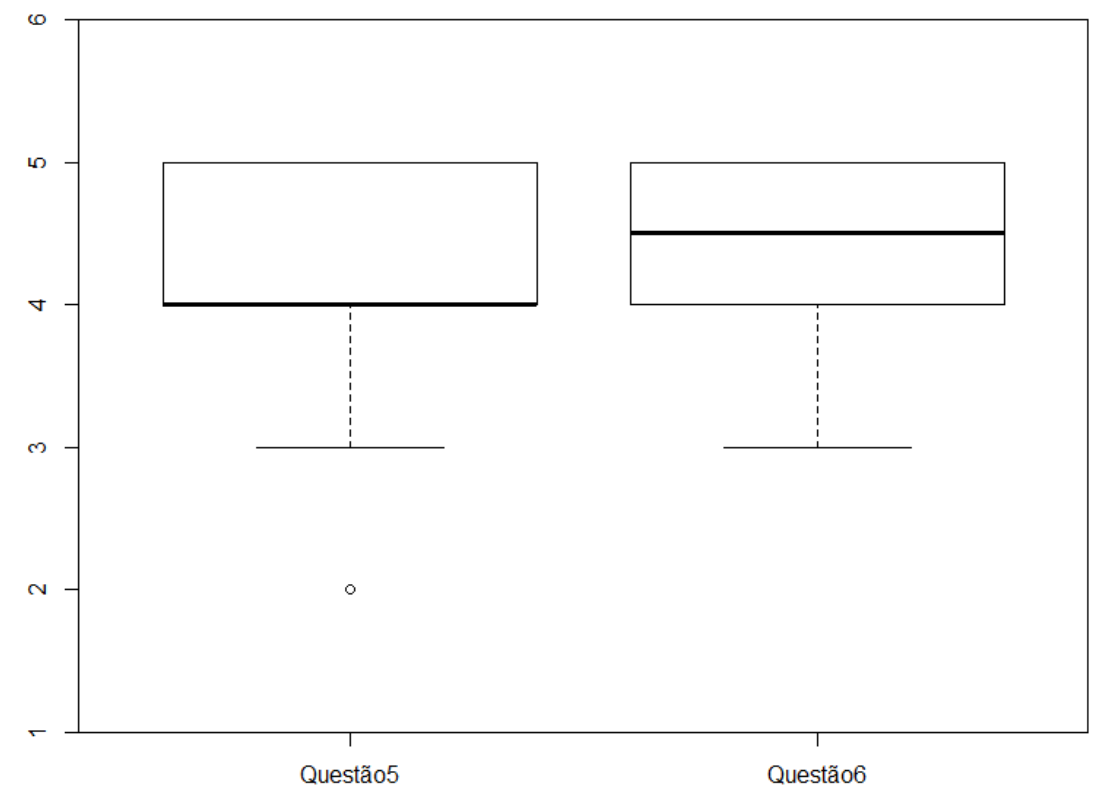

Figura 12. Resultado da avaliação com usuários referente à facilidade de aprendizado.

o aplicativo, o resultado pode ser visto na Figura 13. Pode-se observar que, na primeira pergunta, mais de $75 \%$ dos usuários avaliaram uma resposta 4 ou superior e que, na segunda pergunta, a maioria dos usuários avaliam 1 ou 2, que siginifca nem um pouco desisnteressado.

Além dos resultados das questões de múltipla escolha, o questionário também incluiu duas perguntas. Na primeira pergunta foi perguntado se o usuário teve algum problema da utilização do sistema, onde o mais relatado foi em relação ao tamanho das janelas informativas dento do aplicativo, que segundo as repostas estavam um pouco grandes. Na segunda pergunta foram tratadas possíveis melhorias de funcionalidade, onde foram levantados alguns pontos interessantes como, sugestão de rotas diferenciadas para o percurso ser feito por pedestres e motoristas, sugestão para salvar a rota gerada pelo aplicativo para o usuário consultá-la posteriormente, e um sistema de avaliação dos visitantes sobre cada ponto turístico.

\section{Conclusão}

Embora existam inúmeras ferramentas relacionadas ao turismo, como o TripAdvisor e o Google Maps a ferramenta proposta neste trabalho tem o objetivo de proporcionar aos usuários informações claras e objetivas sobre pontos turísticos, principalmente para cidades de pequeno/médio porte onde muitas vezes as informações estão dispersas.

O método proposto tem como objetivo contribuir para o desenvolvimento turístico das cidades onde geralmente o turista tem que fazer uma longa pesquisa sobre os pontos turísticos da região, visto que, o turismo é um setor muito rico no Brasil, porém muitas vezes pouco explorado. 


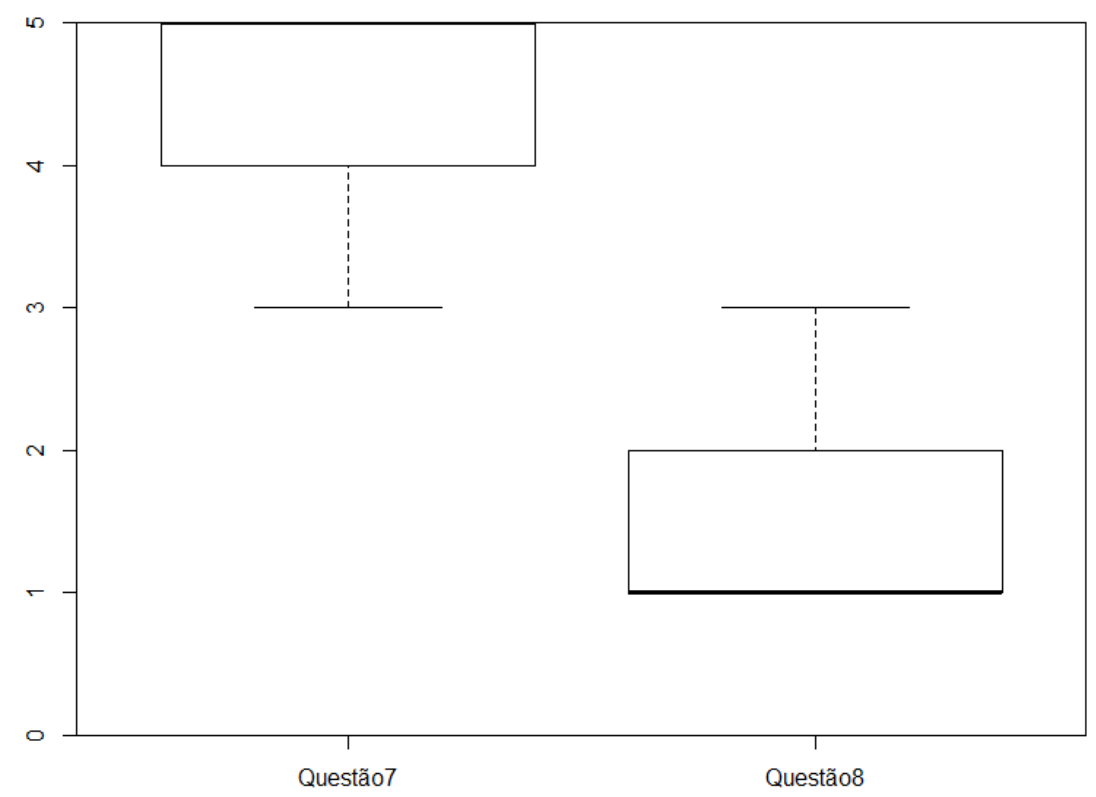

Figura 13. Resultado da avaliação com usuários referente à satisfação dos usuários.

Apesar dos resultados quantitativos e qualitativos produzidos pela avaliação com usuários ainda não serem completamente conclusivos devido ao pequeno número participantes, eles apontam que o sistema proposto atendeu aos requisitos básicos de usabilidade, é capaz de proporcionar uma boa experiência aos usuários e satisfazer as suas expectativas de uso.

Como proposta para trabalhos futuros, com o objetivo de agregar novos recursos à ferramenta, uma direção será o ranqueamento dos pontos turísticos com base no gosto do usuário, assim a indicação de um roteiro usaria além da distância a importância daquele ponto para o turismo local. Pretendemos também, adicionar ao aplicativo possibilidade de exibir rotas diferenciadas para o percurso ser feito por pedestres e motoristas, sugerida pelos participantes da avaliação do aplicativo.

Isto posto, entende-se que este trabalho poderá servir de base para outros trabalhos na área de visualização de informações turísticas, que desde o princípio era um dos objetivos deste estudo.

\section{Referências}

da Silva Júnior, O. S. (2013). Algoritmos para os problemas de roteirização estática e dinâmica de veículos com janelas de tempo. Master's thesis, Pontifícia Universidade Católica do Rio de Janeiro.

DALGAARD, P. (2018). Introductory Statistics with $R$ Statistics and Computing. New York: Springer New York. 
Dias, M. P. (2007). A contribuição da visualização da informação para a ciência da informação. http://twixar.me/Jlhn.

do Nascimento, H. A. D. e Ferreira, C. B. R. (2005). Visualização de informações uma abordagem prática. http://www.lbd.dcc.ufmg.br/colecoes/jai/ $2005 / 002$.pdf.

Freitas, C. M. D. S., Chubachi, O. M., Luzzardi, P. R. G., e Cava, R. A. (2001). Introdução à visualização de informações. https://www.researchgate. net/publication/266863377_Introducao_a_Visualizacao_de_ Informacoes.

OSM. Open street map. www. openstreetmap.org. 